\title{
Lung and chest wall mechanics in normal anaesthetized subjects and in patients with COPD at different PEEP levels
}

\author{
G. Musch*, G. Foti*, M. Cereda*, P. Pelosi**, D. Poppi ${ }^{+}$, A. Pesenti*
}

Lung and chest wall mechanics in normal anaesthetized subjects and in patients with COPD at different PEEP levels. G. Musch, G. Foti, M. Cereda, P. Pelosi, D. Poppi, A. Pesenti. @ERS Journals Ltd 1997.

ABSTRACT: In order to assess the relative contribution of the lung and the chest wall to the derangements of respiratory mechanics in chronic obstructive pulmonary disease (COPD) patients with acute ventilatory failure (AVF), we studied eight COPD patients undergoing controlled mechanical ventilation for AVF and nine normal subjects anaesthetized for surgery as a control group.

With the use of the interrupter technique together with the oesophageal balloon technique we measured: static lung and chest wall elastances $\left(E_{\text {st,L }}\right.$ and $E_{\text {st,w, }}$, respectively), maximum $(R \mathrm{~L}, \mathrm{max})$, minimum $(R \mathrm{~L}, \mathrm{~min})$ and additional $(\Delta R \mathrm{~L})$ lung resistances, additional chest wall resistance $\left(\Delta R_{w}\right)$ and, in the COPD group, total intrinsic positive end-expiratory pressure (PEEPtot). Measurements were repeated at 0,5 , 10 and $15 \mathrm{cmH}_{2} \mathrm{O}$ of applied positive end-expiratory pressure (PEEP).

We found that, in the COPD group: 1) both $E_{\text {st,w }}$ and $\Delta R_{w}$ were higher than in the normal group; 2) $R \mathrm{~L}$,max was markedly increased due to an increase of both $R L$,min and $\triangle R L ; 3)$ even low levels of PEEP increased PEEPtot; 4) PEEP did not reduce elastance or total resistance of either the lung or the chest wall.

We conclude that chest wall mechanics are abnormal in chronic obstructive pulmonary disease patients with acute ventilatory failure undergoing controlled mechanical ventilation and that positive end-expiratory pressure does not seem to be effective in reducing either elastance or resistance of the lung or chest wall.

Eur Respir J 1997; 10: 2545-2552.
* Istituto di Anestesiologia e Rianimazione, Università degli Studi di Milano, and Servizio di Anestesia, Ospedale San Gerardo, Monza, Italy and ** Ospedale Maggiore Policlinico IRCCS, Milano, Italy and +Servizio di Radiologia, Ospedale San Gerardo Monza, Italy.

Correspondence: G. Musch

Servizio di Anestesia e Rianimazione Ospedale San Gerardo

via Donizetti 106

Monza (MI)

20052 Italy

Keywords: Acute ventilatory failure chronic obstructive pulmonary disease mechanical ventilation positive end-expiratory pressure respiratory mechanics

Received: December 301996 Accepted after revision July 111997
The mechanical properties of the total respiratory system in patients with acute exacerbation of chronic obstructive pulmonary disease (COPD) have been extensively investigated, reporting an increase in respiratory resistance as a hallmark $[1,2]$. However, few studies evaluated the relative contribution of the lung and the chest wall to total respiratory system mechanics in COPD patients with acute ventilatory failure (AVF). POLESE et al. [3] found that, in this condition, the alterations of respiratory mechanics are essentially due to the lung rather than to the chest wall. However, KATZ et al. [4] suggested that, at least in some mechanically ventilated patients with acute respiratory failure, chest wall mechanics may be abnormal, and, more recently, an unexpected alteration of chest wall mechanical properties has been reported in patients with adult respiratory distress syndrome [5].

The aim of this study was to further elucidate the alterations of lung and chest wall mechanics during acute exacerbation of COPD requiring mechanical ventilation (MV). We have measured inspiratory resistance and static elastance of the lung and chest wall ( $E_{\mathrm{st}, \mathrm{L}}$ and $E_{\mathrm{st}, \mathrm{w}}$, respectively) in a selected group of COPD patients with $\mathrm{AVF}$, and compared the results with those obtained in a group of normal anaesthetized subjects. Furthermore, since the use of positive end-expiratory pressure (PEEP) in COPD patients undergoing controlled mechanical ven- tilation is still controversial $[2,6]$, we investigated the early effects of acute changes of PEEP upon partitioned respiratory mechanics.

Materials and methods

\section{Study subjects}

Two groups of subjects were studied: anaesthetized patients (normal subjects) and COPD patients.

Normal subjects. Nine control subjects (four females, five males) scheduled to undergo elective surgery entered this group. They were nonsmokers and had neither clinical nor radiological evidence of chronic lung disease or chronic heart failure; the mean age was $48 \pm 12 \mathrm{yrs}$, weight $62 \pm 7 \mathrm{~kg}$, and height $161 \pm 5 \mathrm{~cm}$. Patients received diazepam $\left(0.14 \mathrm{mg} \cdot \mathrm{kg}^{-1}\right)$ 30-45 min before the scheduled surgery time, as pre-anaesthetic medication. Anaesthesia was induced with thiopental $\left(5 \mathrm{mg} \cdot \mathrm{kg}^{-1}\right)$ and succinylcholine $\left(1 \mathrm{mg} \cdot \mathrm{kg}^{-1}\right)$ was given to facilitate orotracheal intubation. Patients were then maintained in air supplemented with oxygen $\left(40 \% \mathrm{O}_{2}\right)$, fentanyl $\left(2-3 \mu \mathrm{g} \cdot \mathrm{kg}^{-1}\right)$ and droperidol $\left(0.1 \mathrm{mg} \cdot \mathrm{kg}^{-1}\right)$ boluses repeated every 30 min, and paralyzed with pancuronium bromide $(0.08$ 
$\left.\mathrm{mg} \cdot \mathrm{kg}^{-1}\right)$. The patients were transorally intubated with an endotracheal tube (7-8 mm internal diameter (ID)) and ventilated with a Siemens Servo 900 C (Siemens, Elema AB, Berlin, Germany) mechanical ventilator, in volume control mode with constant inspiratory flow (table 1).

COPD patients. Eight consecutive patients (three females, five males) admitted to the Intensive Care Unit (ICU) of the University Hospital of Monza, Milan, for acute exacerbation of COPD were studied. The mean age was $61 \pm 14 \mathrm{yrs}$, weight $67 \pm 13 \mathrm{~kg}$, height $165 \pm 9 \mathrm{~cm}$ and duration of intubation at the time of the study $3 \pm 3.7$ days. The diagnosis of COPD was confirmed by history, physical examination, and chest radiography; pulmonary function tests during a period of clinical stability prior to the study were available in six of the eight patients, their mean \pm SD forced expiratory volume in one second was $0.68 \pm 0.23 \mathrm{~L}$ and forced vital capacity $1.34 \pm 0.58 \mathrm{~L}$. Chest radiographs taken the day of the study were evaluated by an expert radiologist for the presence of pulmonary infiltrates, pleural effusion and signs of pulmonary oedema. Pulmonary infiltrates were present in four of the eight patients. Unilateral pleural effusions were present in three patients. With reference to a four grade scale (slight, mild, moderate, severe), two were classified as showing slight and one mild pleural effusions. No signs of either interstitial or alveolar pulmonary oedema were detected. In six of the eight patients, in whom a SwanGanz catheter had been inserted by the attending physician, pulmonary wedge pressure was $1.5 \pm 0.3 \mathrm{kPa}(11 \pm 2$ $\mathrm{mmHg}$ ) (range $0.9-1.9 \mathrm{kPa}(7-14 \mathrm{mmHg})$ ). None of our patients had a history of heart disease; though one was being treated for essential hypertension. Patients were sedated with fentanyl $\left(2-3 \mu \mathrm{g} \cdot \mathrm{kg}^{-1} \cdot \mathrm{h}^{-1}\right)$ and paralyzed with pancuronium bromide boluses $\left(0.06 \mathrm{mg} \cdot \mathrm{kg}^{-1}\right)$. Seven of the eight patients were receiving aminophylline infusion $\left(0.45-0.6 \mathrm{mg} \cdot \mathrm{min}^{-1}\right)$, five methylprednisolone $(2$ $\mathrm{mg} \cdot \mathrm{kg}^{-1} \cdot \mathrm{day}^{-1}$ in four doses) and six salbutamol (5-20 $\left.\mu \mathrm{g} \cdot \mathrm{min}^{-1}\right)$ at the time of the study. Seven patients were nasotracheally intubated with a cuffed endotracheal tube $(7-8.5 \mathrm{~mm})$ and one had a tracheostomy cannula $(9 \mathrm{~mm}$ ID). All patients were ventilated with a Siemens Servo $900 \mathrm{C}$ mechanical ventilator, in volume control mode with constant inspiratory flow (table 1).

Baseline ventilatory parameters and gas exchange, before the study, are reported in table 1 .

\section{Study design}

In both groups, the elastic and flow resistive properties of lung and chest wall were measured at different PEEP levels. Except for changes in applied PEEP the ventilatory parameters, that had been previously set by the attending physician, were kept constant throughout the experiment. PEEP levels of 0, 5, 10 and $15 \mathrm{cmH}_{2} \mathrm{O}$ were applied in random order and maintained for at least 5 min before taking measurements. The entire protocol took 40-50 min in both groups. In all subjects the electrocardiogram, cardiac frequency and arterial oxygen saturation were continuously monitored throughout the study. In the COPD group arterial and central venous pressure were also continuously monitored, whereas in
Table 1. - Baseline ventilatory parameters and arterial blood gases in normal subjects and in patients with chronic obstructive pulmonary disease (COPD)

\begin{tabular}{lcc}
\hline & Normal & COPD \\
\hline$V \mathrm{~T} \mathrm{~L}$ & $0.59 \pm 0.1$ & $0.62 \pm 0.1$ \\
$f \mathrm{R} \mathrm{bpm}$ & $13.8 \pm 0.4$ & $13.9 \pm 2.2$ \\
$t \mathrm{I} \mathrm{s}$ & $1.04 \pm 0.05$ & $0.98 \pm 0.17$ \\
$V^{1} \mathrm{I} \mathrm{L} \cdot \mathrm{s}^{-1}$ & $0.56 \pm 0.08$ & $0.65 \pm 0.16$ \\
$\mathrm{PEEP} \mathrm{cmH} \mathrm{Cm}_{2} \mathrm{O}$ & - & $4.6 \pm 3.9$ \\
$F \mathrm{I}, \mathrm{O}_{2}$ & $0.4 \pm 0.04$ & $0.5 \pm 0.1$ \\
$\mathrm{~Pa}_{2} \mathrm{O}_{2} \mathrm{mmHg}$ & $171 \pm 51$ & $85.3 \pm 16.1$ \\
$P \mathrm{a}, \mathrm{CO}_{2} \mathrm{mmHg}$ & $37.0 \pm 2.2$ & $55.2 \pm 10.3$ \\
$\mathrm{pH}$ & $7.41 \pm 0.04$ & $7.41 \pm 0.06$ \\
\hline
\end{tabular}

Values are expressed as mean \pm SD. $V \mathrm{~T}$ : tidal volume; $f \mathrm{R}$ : respiratory frequency; bpm: beats per minute; $t \mathrm{t}$ : inspiratory time; $V^{\prime}$ I: inspiratory flow; PEEP: positive end-expiratory pressure (PEEP set by the attending physician before entry into the study); $\mathrm{FI}, \mathrm{O}_{2}$ : inspired oxygen fraction; $\mathrm{Pa}_{\mathrm{a}} \mathrm{O}_{2}$ : arterial oxygen pressure; $\mathrm{Pa}_{\mathrm{a}} \mathrm{CO}_{2}$ : arterial carbon dioxide pressure.

the normal group arterial pressure was measured intermittently and noninvasively. We were able to complete the study protocol in all patients, without significant adverse cardiovascular effects. A physician not involved in the study was always present to provide care for the patients.

The study was approved by the institutional ethics committee and informed consent was obtained from the patients or from their next of kin before entry into the study.

\section{Physiological measurements}

Gas flow $\left(V^{\prime}\right)$ was measured with a heated pneumotachograph (Fleisch no. 2; Fleisch, Lausanne, Switzerland), placed between the Y-piece of the ventilator and the artificial airway and connected to a Validyne MP 451 differential pressure transducer (Validyne Corp., Northridge, CA., USA). The pneumotachograph was calibrated with the experimental gas mixture, and its response was linear over the experimental range of flows. Volume was determined by digital integration of the flow signal.

Airway pressure $(P$ aw $)$ was measured at the proximal end of the endotracheal tube or tracheostomy cannula by means of a polyethylene tubing ( $2 \mathrm{~mm} \mathrm{ID,} 100 \mathrm{~cm}$ long) connected to a Bentley Trantec pressure transducer (Bentley Laboratories, Irvine, CA, USA). Oesophageal pressure $\left(P_{\text {oes }}\right)$ was measured with a similar transducer connected through a polyethylene catheter ( $2 \mathrm{~mm}$ ID, $100 \mathrm{~cm}$ long) to a thin-walled latex oesophageal balloon (Bicore, Irvine, CA, USA), filled with approximately $1 \mathrm{~mL}$ of air. The validity of $P$ oes measurements was assessed with the "occlusion test" method [7]. In the normal group after the effect of succinylcholine had ceased, the occlusion test was performed to correctly position the oesophageal balloon and pancuronium bromide was then administered; in the COPD group the occlusion test was performed immediately before paralysis. With this recording system, $P$ aw and $P$ oes measurements were not affected by phase shift or alteration in amplitude up to $20 \mathrm{~Hz}$. Flow and pressure signals were recorded on a four channel pen recorder (Battaglia 
Rangoni, Bologna, Italy) and processed via an analogue to digital converter (100 Hz sampling rate) by an IBM personal computer (IBM, Armonk, NY, USA) for storage and calculations.

The pressure-flow relationship of the artificial airway was determined in vitro with the same gas mixture used during the in vivo experiments. These relationships were then used to estimate the resistive pressure drop across the endotracheal tube or tracheostomy cannula for any given flow during tests. This method has been extensively described and validated by BeHRAKIS et al. [8]. Subjects were connected to the ventilator by standard adult low-compliance tubing ( $2 \mathrm{~cm}$ ID, $110 \mathrm{~cm}$ long) and the humidifier was removed during the experiments in order to reduce the effects of resistance and compliance of the system upon physiological measurements.

Respiratory mechanics were measured using the endinspiratory occlusion (EIO) technique during constant flow inflation [9] and the end-expiratory occlusion (EEO) method [10]. The oesophageal balloon technique allowed partitioning of total respiratory system mechanics into their lung and chest wall components $[3,11]$.

As shown in figure 1, the EIO was followed by an immediate drop in $P$ aw from a maximum value ( $P$ aw,max $)$ to a lower, zero flow. value $(P$ aw, 1$)$. and then by a slow decay to a plateau $(P$ aw, 2$)$; on the $P$ oes tracing, only a maximum $\left(P_{\text {oes, }}\right.$ max $)$ and a plateau $\left(P_{\text {oes }}, 2\right)$ value were clearly identified and no rapid decrease was evident following airway occlusion (i.e. Poes, 1 could not be identified) in line with what has already been reported by other authors $[5,11,12]$. Paw,max was corrected for the resistive pressure drop due to the artificial airway, as described above, and the corrected value was used for all calculations involving $P$ aw,max. $P$ aw, 1 was measured by back extrapolation of a computer fitted curve to the time corresponding to $P$ aw,max. Measurements of $P$ aw, 2 and $P_{\text {oes, }} 2$ were taken $4 \mathrm{~s}$ after the onset of the EIO. We were thus able to compute:

minimum lung resistance $(R \mathrm{~L}, \mathrm{~min})=(P \mathrm{aw}, \max -P$ aw, 1$) / V^{\prime}$ additional lung resistance $(\Delta R \mathrm{~L})=((P$ aw, $1-P$ oes,max $)-$

$$
(P \text { aw }, 2-P \text { oes }, 2)) / V^{\prime}
$$

maximum lung resistance $(R \mathrm{~L}, \max )=\left(\left(P\right.\right.$ aw, max $\left.-P_{\text {oes, } m a x}\right)-$ $(P$ aw, $2-P$ oes, 2$)) / V^{\prime}=R \mathrm{~L}, \min +\Delta R \mathrm{~L}$

where $V^{\prime}$ is the gas flow immediately preceding the EIO.

Values of $R \mathrm{~L}$, min were corrected for the closing time of the Servo 900C ventilator valve as previously described [13]. Since no $P_{\text {oes, } 1}$ value could be clearly identified in either normal or COPD subjects, it follows that we were not able to detect any appreciable purely ohmic chest wall resistance. This implies that:

chest wall resistance $R \mathrm{w}, \max =\Delta R_{\mathrm{w}}=\left(P_{\mathrm{oes}}, \max -P_{\mathrm{oes}}, 2\right) / V^{\prime}$

According to the analysis by BATES et al. [9], Rmin represents airway resistance and is, therefore, also referred to as "ohmic" resistance, whereas additional resistance, denoted as $\Delta \mathrm{R}$, should reflect viscoelastic phenomena (i.e. stress relaxation) of thoracic tissues and/or gas redistribution due to time constant inequalities (i.e. pendelluft) among alveolar units.

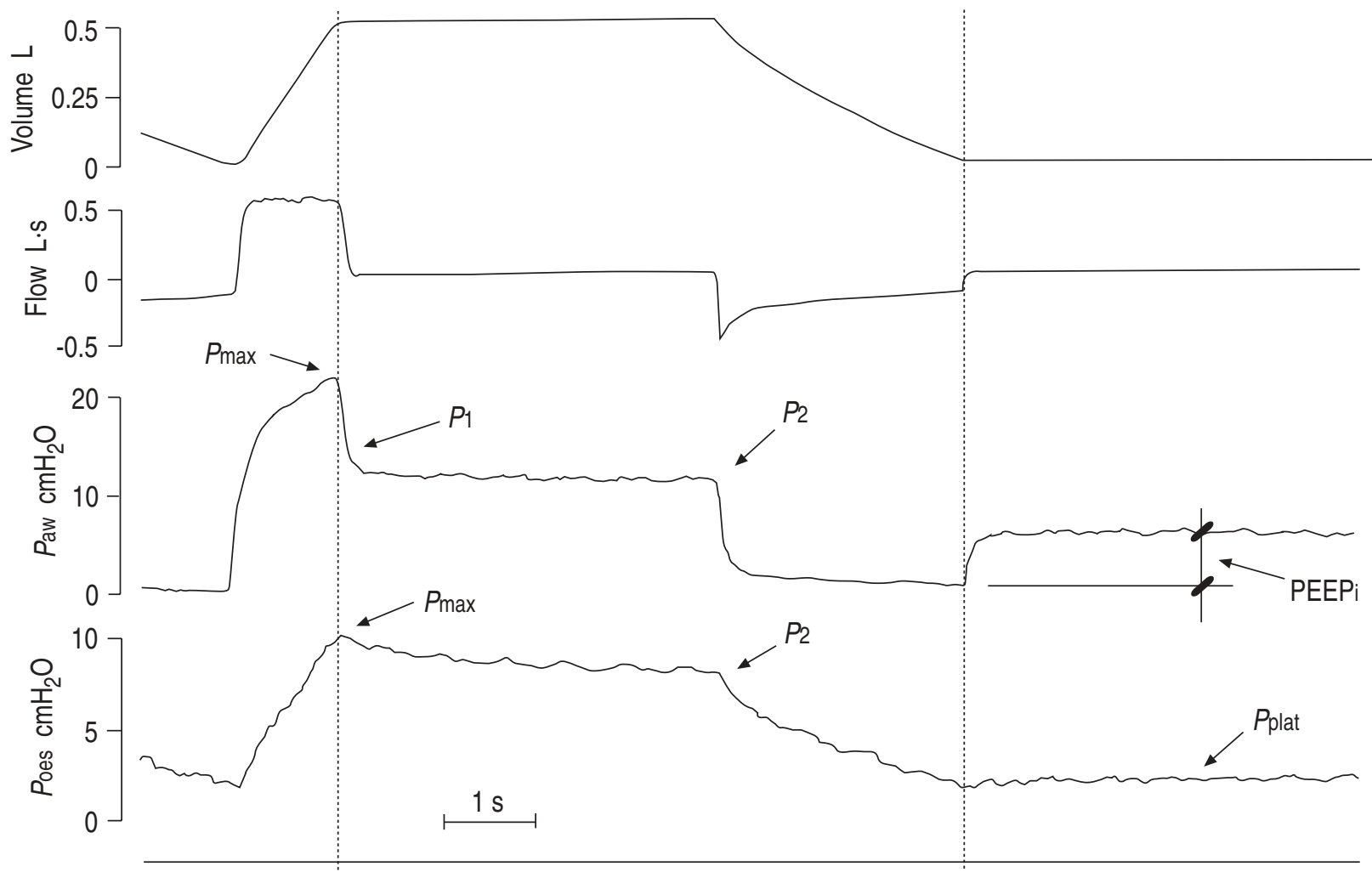

Time s

Fig. 1. - Tracings of volume (obtained by integration of the flow signal), flow, airway pressure $\left(P_{\text {aw }}\right)$ and oesophageal pressure $\left(P_{\mathrm{oes}}\right)$ in a representative patient with chronic obstructive pulmonary disease (COPD) during an end inspiratory occlusion followed by an end expiratory occlusion. ........ : indicate timing of occlusions. $P$ max: maximum value; $P 1$ : zero flow value; $P_{2}$ : plateau value; PEEPi: intrinsic positive end-expiratory pressure is the static end-expiratory recoil pressure of the respiratory system; $P$ plat: plateau value of $P$ oes after end-expiratory occlusion. Values of $P$ aw,max, used for calculations were corrected for the resistive pressure drop due to the artificial airway. See text for further explanations. 
An EEO from a COPD patient is shown in figure 1. Whereas in the normal subjects $P$ aw did not appreciably change after the occlusion, in the COPD patients there was a rise in $P$ aw following the occlusion towards a plateau value, which represents the static end-expiratory recoil pressure of the respiratory system, and that has been referred to as intrinsic PEEP (PEEPi) [1], autoPEEP [2] or occult PEEP [10]. All of our COPD patients exhibited a PEEPi. We will henceforth denote the absolute postocclusion plateau $P$ aw value as PEEPtot and the difference between PEEPtot and the preocclusion endexpiratory $P$ aw value as PEEPi. On the $P$ oes tracing, the postocclusion plateau $P_{\text {oes }}$ pressure $\left(P_{\text {oes,plat}}\right)$ was used to compute elastances.

$E_{\text {st,L }}$ and $E_{\text {st,w }}$ were calculated as follows:

$$
\begin{gathered}
E_{\mathrm{st}, \mathrm{L}}=\left(\left(P_{\mathrm{aw}, 2-}-P_{\text {oes }}, 2\right)-\left(\text { PEEPtot }-P_{\text {oes }, \text { plat }}\right)\right) / V \mathrm{~T}, \mathrm{I} \\
E_{\mathrm{st}, \mathrm{w}}=\left(P_{\mathrm{oes}, 2}-P_{\text {oes }} \text { plat }\right) / V \mathrm{~T}, \mathrm{I}
\end{gathered}
$$

where $V$ T,I is inspiratory tidal volume.

\section{Statistical analysis}

Values are expressed as mean \pm SEM unless otherwise specified. The study was planned according to a splitplot experimental design in which each patient represented a randomized block and analysis of variance (ANOVA) allowed evaluation of the global effect of disease, of the effect of PEEP and of the eventual interaction between groups and PEEP [14]. Only when ANOVA revealed significant overall differences between the two groups, were further comparisons between selected means from the two groups performed by Student's t-test for unpaired data. Zero end-expiratory pressure (ZEEP) was arbitrarily chosen for these comparisons, and differences at higher PEEP levels were tested only when differences at ZEEP were not statistically significant, despite significant overall differences between the two groups as revealed by ANOVA. When a significant interaction between groups and PEEP was detected, the effect of PEEP was assessed separately in the COPD and normal groups by two-way ANOVA [14]. Student's t-test for paired data was used for within group comparisons between different levels of PEEP. A p-value of less than 0.05 was considered significant.

\section{Results}

Elastances of the lung and chest wall are shown in table 2. At ZEEP, Est,w was significantly higher in patients with COPD than in the normal subjects $(p<0.01)$. Furthermore, PEEP decreased $E$ st,w in the normal group $(\mathrm{p}<0.05)$, whereas it did not significantly affect $E_{\text {st,w }}$ in the COPD group. Est,L did not differ between the two groups and it increased with PEEP in both COPD and normal subjects $(\mathrm{p}<0.05)$ with no significant interaction between groups and PEEP.

Resistances of the lung and chest wall are shown in table 3. At ZEEP, RL, max was markedly elevated in patients with COPD compared to the normal subjects $(\mathrm{p}<0.01)$. This increase in $R \mathrm{~L}$, max was due mainly to higher $R \mathrm{~L}$,min $(\mathrm{p}<0.01)$ but also to an increased $\Delta R \mathrm{~L}$
Table 2. - Static lung and chest wall elastance (Est,L and Est,w, respectively) in normal subjects and in patients

\begin{tabular}{|c|c|c|c|c|}
\hline & \multicolumn{4}{|c|}{ PEEP $\mathrm{cmH}_{2} \mathrm{O}$} \\
\hline & 0 & 5 & 10 & 15 \\
\hline \multicolumn{5}{|c|}{$E_{\mathrm{st}, \mathrm{L}} \quad \mathrm{cmH}_{2} \mathrm{O} \cdot \mathrm{L}^{-1}$} \\
\hline Normal* & $8.7 \pm 0.5$ & $9.5 \pm 0.5$ & $9.6 \pm 0.5$ & $9.7 \pm 0.6$ \\
\hline COPD* & $9.2 \pm 2.0$ & $9.7 \pm 2.0$ & $10.3 \pm 2.6$ & $12.6 \pm 2.9$ \\
\hline \multicolumn{5}{|c|}{$E_{\mathrm{st}, \mathrm{w}} \quad \mathrm{cmH}_{2} \mathrm{O} \cdot \mathrm{L}^{-1+\ddagger}$} \\
\hline Normal* & $6.2 \pm 0.3$ & $4.5 \pm 0.5$ & $4.2 \pm 0.4$ & $3.9 \pm 0.5$ \\
\hline COPD & $8.9 \pm 0.9^{\S}$ & $8.7 \pm 0.8$ & $8.6 \pm 0.6$ & $9.4 \pm 1.2$ \\
\hline
\end{tabular}
with chronic obstructive pulmonary disease (COPD)

Values are expressed as mean \pm SEM. PEEP: positive end-expiratory pressure. *: Significantly different between PEEP 0,5 , 10 and $15 \mathrm{cmH}_{2} \mathrm{O}(\mathrm{p}<0.05)$; +: significant interaction between groups and PEEP $(\mathrm{p}<0.05)$; : significantly different between COPD and Normal $(\mathrm{p}<0.01)$; $\$$ : significantly different from the corresponding value of the normal group $(\mathrm{p}<0.01)$.

Table 3. - Lung and chest wall resistances in normal

\begin{tabular}{|c|c|c|c|c|}
\hline & \multicolumn{4}{|c|}{ PEEP $\mathrm{cmH}_{2} \mathrm{O}$} \\
\hline & 0 & 5 & 10 & 15 \\
\hline \multicolumn{5}{|c|}{$R \mathrm{~L}, \max \quad \mathrm{cmH}_{2} \mathrm{O} \cdot \mathrm{L}^{-1} \cdot \mathrm{s}^{+}$} \\
\hline Normal & $3.2 \pm 0.4$ & $2.7 \pm 0.3$ & $2.5 \pm 0.2$ & $2.3 \pm 0.3$ \\
\hline COPD & $17.6 \pm 2.9^{* *}$ & $18.1 \pm 3.2$ & $17.8 \pm 3.0$ & $17.2 \pm 2.9$ \\
\hline \multicolumn{5}{|c|}{$R \mathrm{~L}, \min \quad \mathrm{cmH}_{2} \mathrm{O} \cdot \mathrm{L}^{-1} \cdot \mathrm{s}^{\dagger+}$} \\
\hline Normal§ & $2.1 \pm 0.4$ & $1.8 \pm 0.3$ & $1.6 \pm 0.2$ & $1.0 \pm 0.2$ \\
\hline $\mathrm{COPD}^{\S}$ & $11.5 \pm 1.8^{* *}$ & $11.1 \pm 1.8$ & $9.6 \pm 1.8$ & $7.8 \pm 1.3$ \\
\hline \multicolumn{5}{|c|}{$\Delta R \mathrm{~L} \quad \mathrm{cmH}_{2} \mathrm{O} \cdot \mathrm{L}^{-1} \cdot \mathrm{s}^{\dagger+}$} \\
\hline Normal & $1.1 \pm 0.2$ & $0.9 \pm 0.2$ & $0.9 \pm 0.2$ & $1.2 \pm 0.4$ \\
\hline $\mathrm{COPD}^{\S}$ & $6.1 \pm 2.0 *$ & $7.0 \pm 2.1$ & $8.2 \pm 2.0$ & $9.4 \pm 2.2$ \\
\hline \multicolumn{5}{|c|}{$\Delta R \mathrm{w} \quad \mathrm{cmH}_{2} \mathrm{O} \cdot \mathrm{L}^{-1} \cdot \mathrm{s}^{\dagger+}$} \\
\hline Normal & $0.9 \pm 0.2$ & $0.7 \pm 0.1$ & $0.8 \pm 0.1$ & $0.7 \pm 0.1$ \\
\hline COPD $\S$ & $1.4 \pm 0.2$ & $1.6 \pm 0.3 * *$ & $2.3 \pm 0.4 * *$ & $3.0 \pm 0.6 * *$ \\
\hline
\end{tabular}
subjects and in patients with COPD

Values are expressed as mean \pm SEM. $R \mathrm{~L}$,max: maximum lung resistance; $R \mathrm{~L}$,min: minimum lung resistance; $\Delta R \mathrm{~L}$ : additional lung resistance; $\Delta R_{\mathrm{w}}$ : additional chest wall resistance; +: significantly different between COPD and Normal $(\mathrm{p}<0.01)$; **: significantly different from the corresponding value of the normal group $(\mathrm{p}<0.01) ; \uparrow$ : significant interaction between groups and PEEP $(\mathrm{p}<0.01)$; §: significantly different between PEEP $0,5,10$ and $15 \mathrm{~cm} \mathrm{H}_{2} \mathrm{O}(\mathrm{p}<0.01)$; *: significantly different from the corresponding value of the normal group $(p<0.05)$. For further definitions refer to table 1.

$(\mathrm{p}<0.05)$ compared with the normal group. PEEP did not affect $R \mathrm{~L}$,max in the COPD subjects, although it did cause a substantial redistribution between its components by increasing $\Delta R \mathrm{~L}(\mathrm{p}<0.01)$ and decreasing $R \mathrm{~L}$, min $(\mathrm{p}<0.01)$. At ZEEP, $\Delta R_{\mathrm{w}}$ was higher in the COPD than in the normal group, although it did not reach statistical significance $(\mathrm{p}<0.1)$; split-plot analysis, however, revealed a significant interaction between groups and PEEP $(\mathrm{p}<0.01)$, due to the fact that $\Delta R \mathrm{w}$ increased with PEEP in the COPD patients $(\mathrm{p}<0.01)$, whereas it did not in the normal subjects. At PEEP $5 \mathrm{cmH}_{2} \mathrm{O}$ and higher, $\Delta R \mathrm{w}$ was significantly higher in the COPD than in the normal group $(\mathrm{p}<0.01)$.

Values of PEEPi and PEEPtot in the COPD group are shown in figure 2. As applied PEEP was raised from 0 to $15 \mathrm{~cm} \mathrm{H}_{2} \mathrm{O}$, PEEPi significantly decreased $(\mathrm{p}<0.01)$ and PEEPtot increased $(\mathrm{p}<0.01)$. PEEPtot was significantly higher at $5 \mathrm{cmH}_{2} \mathrm{O}$ than at ZEEP $(9.3 \pm 1.0$ versus $\left.7.5 \pm 1.2 \mathrm{cmH}_{2} \mathrm{O}, \mathrm{p}<0.01\right)$ the values at 10 and $15 \mathrm{cmH}_{2} \mathrm{O}$ 


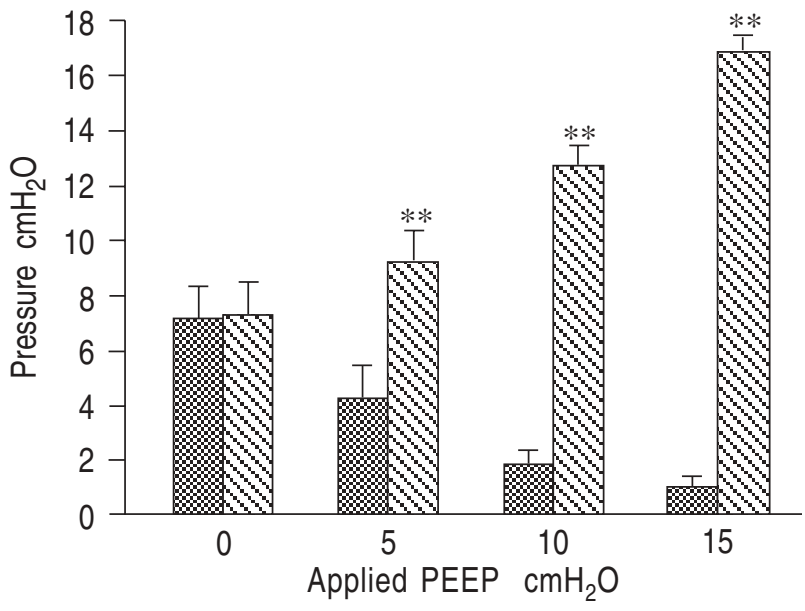

Fig. 2. - Intrinsic positive end-expiratory pressure (PEEPi; $\square$ ) and postocclusion plateau airway pressure (PEEPtot; $\square$ ) in patients with chronic obstructive pulmonary disease at five levels of applied positive end-expiratory pressure (PEEP). Values are presented as mean \pm SEM. **: $\mathrm{p}<0.01$ versus $0 \mathrm{cmH}_{2} \mathrm{O}$ applied PEEP.

were also significantly higher than ZEEP ( $p<0.01)$. In two COPD patients, $\mathrm{PEEP}$ i at ZEEP was lower than $5 \mathrm{cmH}_{2} \mathrm{O}$. We then repeated the above analysis of PEEPtot in only the six patients who had a PEEPi at ZEEP greater than $5 \mathrm{cmH}_{2} \mathrm{O}$, and found that PEEPtot still increased significantly with PEEP, even at PEEP $5 \mathrm{cmH}_{2} \mathrm{O}$ (in these six patients PEEPtot was $8.7 \pm 1.1 \mathrm{cmH}_{2} \mathrm{O}$ at ZEEP versus $10.4 \pm 1.0 \mathrm{cmH}_{2} \mathrm{O}$ at PEEP $\left.5 \mathrm{cmH}_{2} \mathrm{O}, \mathrm{p}<0.01\right)$.

\section{Discussion}

The main results of this study are that: 1) the chest wall showed altered mechanical properties in our mechanically ventilated COPD patients, since both $E_{\text {st,w }}$ and $\Delta R_{\mathrm{w}}$ were increased when compared with the normal subjects; 2) the lung showed higher total resistance in the COPD group due to an increase of both $R \mathrm{~L}$,min and $\triangle R \mathrm{~L}$; 3) even low levels of PEEP increased PEEPtot in the COPD group; 4) PEEP decreased $E_{\text {st,w }}$ in the normal subjects but not in the COPD patients and increased $\Delta R \mathrm{w}$ in the COPD but not in the normal group. Unexpectedly, PEEP did not decrease $R \mathrm{~L}$, max in the COPD group.

\section{Comparison of COPD versus normal groups}

Chest wall and lung elastance. Est,w was significantly higher in our COPD than in our normal subjects: this result was unexpected on the basis of previous experimental and clinical work that failed to show an increase in $E_{\text {st,w }}$ in either emphysematous animals [15] or subjects [12, 16, 17]. RANIERI et al. [18] reported even higher values of Est,w in COPD patients with AVF undergoing MV $\left(10.7 \pm 1.4 \mathrm{cmH}_{2} \mathrm{O} \cdot \mathrm{L}^{-1}\right)$. Therefore, it seems that an increased $E_{\text {st, w }}$ often adds to the derangements of respiratory mechanics that characterize exacerbated COPD. We may hypothesize that several factors contributed to our finding. Altered intestinal, especially colonic motility, eventually leading to colonic pseudo-obstruction, has been shown to occur with an unexpectedly high frequency in mechanically ventilated COPD patients with
AVF [19]; narcotic sedation, which is frequently used in the ICU, may further aggravate this condition [20]. The resulting abdominal distension might increase $E_{\text {st,w }}$ [21]. In four of our eight patients the attending physician reported intestinal hypomotility and abdominal distension as a relevant clinical problem. Narcotics, especially fentanyl, may also cause chest wall rigidity through a central effect [22]. It is unlikely, though, that this effect contributed to the observed abnormal $E$ st,w, since our patients were receiving neuromuscular blocking agents at the time of the study. In patients with AVF undergoing MV, the chest wall static mechanical properties might be also altered by tissue oedema [4]. Furthermore, a recent experimental study has demonstrated that volume infusion induces chest wall stiffening [23]; although extrapolation of these experimental data to the clinical setting must be taken with caution, it might be that fluid loading, which is frequent in ICU patients undergoing MV, contributed to chest wall stiffening. Finally, the presence of pleural effusions might have contributed to increased $E$ st,w in three of our COPD patients. All these factors are peculiar to exacerbations of COPD so severe as to require $\mathrm{MV}$, and this might explain the discrepancy between our results and those of previous investigators who did not observe an increase in $E_{\text {st, }}$ in stable COPD subjects who volunteered to undergo anaesthesia paralysis for the purpose of the study [16, 17]. Although the effect of age cannot be completely discarded, we think that the relatively small difference in age between COPD and control groups did not substantially affect our results.

$E$ st,L did not differ between our COPD and normal subjects and $E$ st,L in our COPD group was only slightly higher than that reported by other authors in similar patients [3, 12], but much higher than that reported for stable COPD subjects $\left(3.8 \mathrm{cmH}_{2} \mathrm{O} \cdot \mathrm{L}^{-1}\right)$ [17]. Several hypotheses may account for this result. Firstly, it is possible that the patients of VAN LiTH et al. [17] had a greater degree of pulmonary emphysema. Secondly, this result may be attributed to the acute inflammatory lung process responsible for the exacerbation of COPD. Pulmonary infiltrates and pleural effusions, which were present in some of our patients were likely implicated in this increase of $E_{\mathrm{st}, \mathrm{L}}$ as compared to stable COPD. A recent experimental study has demonstrated that effusate loading of the pleural space may in fact result in increased lung elastance [24].

Lung and chest wall resistance. RL,min, which represents airway resistance $[9,11]$ was significantly higher in COPD compared to normal subjects as expected.

The increase of $R \mathrm{~L}$, max in the COPD group, though, was due not only to a higher $R \mathrm{~L}$, min but also to a significantly higher $\Delta R \mathrm{~L}$. Since inspiratory time was quite similar in our two groups, this finding might reflect increased stress relaxation of lung tissues but also substantial time constant inhomogeneities among different alveolar units which are likely to exist in COPD patients $[2,25]$.

Similarly to other authors $[5,11,12]$, we did not measure an appreciable ohmic (interrupter) resistance of the chest wall, as we did not identify Poes,1. A different technical approach, such as the use of a more rapid airway shutter valve [26], may allow the recognition of $P_{\text {oes, }} 1$. 
However, the interrupter resistance of the chest wall that can be thus measured is rather small $\left(0.4 \mathrm{cmH}_{2} \mathrm{O} \cdot \mathrm{L} \cdot \mathrm{s}\right.$ [26]) and is, probably, not a significant portion of the high $R$ L,min observed in our COPD patients.

Chest wall resistance was higher in our COPD than in our normal group. GUERIN et al. [12] measured $\Delta R_{\mathrm{w}}$ at different inspiratory flows and inflation volumes in 10 COPD patients and found consistently higher values than for the 18 normal subjects studied by D'ANGELo et al. [11], at the same flow and volume. They suggested that the older age of the COPD subjects might partially explain the difference in $\Delta R \mathrm{w}$. However, in our study there was only a relatively minor difference in age between COPD and control group and, in any case, the age gap between the two groups was much narrower than in the study of GuERIN et al. [12]. SHARP et al. [27] found an increased stress relaxation of the chest wall in patients with ankylosing spondylitis, suggesting that rheological properties of chest wall tissues may be abnormal in restrictive disease of the thorax. Our data seem to suggest that rheology of chest wall tissues is also altered in exacerbated obstructive pulmonary disease.

\section{Effects of PEEP}

PEEP $i$ in the COPD group. The presence of flow limitation during passive exhalation and of heterogeneous lung emptying was suggested, in our patients, by expiratory flow-volume curves that showed an upward concavity due to the presence of a flow spike at the beginning of exhalation followed by lower expiratory flows [28, 29]. A flow-volume curve, obtained during passive exhalation at ZEEP in one of our patients, is shown in figure 3. The interaction between PEEPi and externally applied PEEP, and hence the effects that PEEP might exert upon respiratory mechanics in COPD, depend upon the underlying mechanism generating PEEPi $[2,6]$. If flow limitation is prevalent and homogeneous among different alveolar units, then PEEP values lower than airway pressure at the "choke point" ( $P$ crit) should not

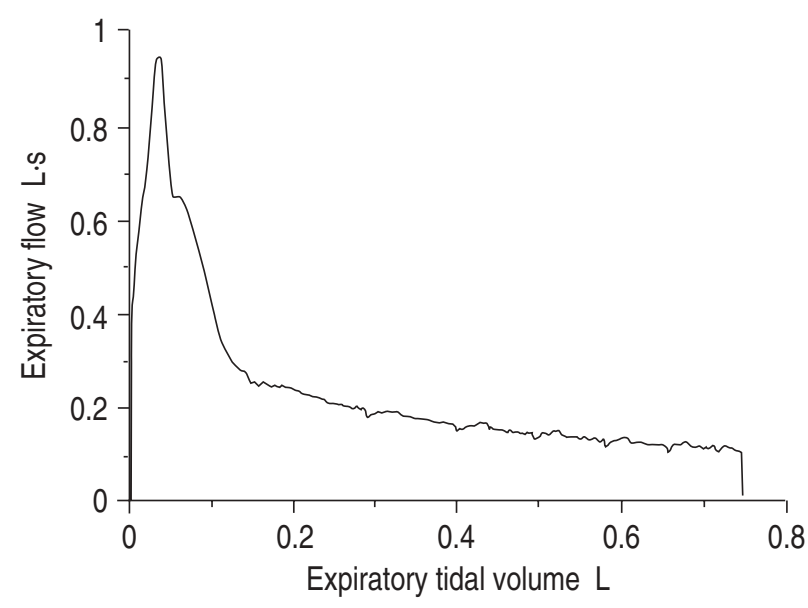

Fig. 3. - Expiratory flow volume curve during passive exhalation at zero end-expiratory pressure in a patient with chronic obstructive pulmonary disease. Notice the bowing towards the volume axis i.e. upward concavity) especially during the first part of exhalation, which suggests the presence of flow limitation $[26,27]$. affect expiratory flow and hence neither upstream alveolar pressure nor lung volume. This implies that PEEPi is expected to decrease by an amount equal to applied PEEP, with the consequence that PEEPtot should not change until applied PEEP equals $P$ crit. Data reported by RANIERI et al. [18] are consistent with the above reasoning and indicate $85 \%$ of PEEPi on ZEEP as the PEEP threshold that does not affect PEEPtot $(P$ crit). Our results are not as clear-cut as theirs, since even our low PEEP level of $5 \mathrm{cmH}_{2} \mathrm{O}$, which represented only $70 \%$ of average PEEPi on ZEEP $\left(7.1 \pm 1.2 \mathrm{cmH}_{2} \mathrm{O}\right)$, was associated with an increase in PEEPtot from $7.5 \pm 1.2$ to $9.3 \pm 1.0$ $\mathrm{cmH}_{2} \mathrm{O}$ (fig. 2). When data only from the patients with PEEPi on ZEEP greater than $5 \mathrm{cmH}_{2} \mathrm{O}$ were compared, PEEPtot was still found to increase significantly from $8.7 \pm 1.1$ to $10.4 \pm 1.0 \mathrm{cmH}_{2} \mathrm{O}$ with $5 \mathrm{cmH}_{2} \mathrm{O}$ of applied PEEP. This implies that even low PEEP, below $85 \%$ of PEEPi on ZEEP, induced further, although presumably small, hyperinflation in our patients. At present there is theoretical, experimental and clinical evidence to suggest that lung mechanics in obstructive disease is highly heterogeneous [2, 29]: open non-flow-limited alveolar units are likely to coexist with flow-limited and functionally closed ones. In such a nonhomogeneous lung model, even low levels of applied PEEP would cause further hyperinflation by increasing upstream alveolar pressure in both non-flow-limited units and in flow-limited units with the lowest $P$ crit once PEEP reverses dynamic airway collapse.

Although we wished to investigate the effects of PEEP on respiratory mechanics, we can speculate that PEEP might have affected gas exchange. Moderate levels of PEEP can lead to improvements in gas exchange and decreases in the ventilation-perfusion mismatch, in COPD patients [30].

Chest wall and lung elastance. The progressive decrease in Est,w with PEEP in our normal individuals could have been anticipated on the basis of the chest wall V-P curve which shows a progressively increasing slope over the whole vital capacity range [31]. In contrast, PEEP did not significantly modify $E_{\mathrm{st}, \mathrm{w}}$ in our COPD patients, although average $E$ st,w increased slightly at high PEEP. Information on the chest wall V-P curve in COPD patients is still sparse. SHARP et al. [16] found that, in emphysema, V-P curves of the thorax remained linear up to volumes higher than predicted total lung capacity. Their chest wall mechanics data, however, were obtained from stable COPD patients. Since we did not measure endexpiratory lung volume, we were not able to draw V-P curves in our patients. However, this was done in a very recent study by RANIERI et al. [32] in which the authors found that COPD patients undergoing MV for AVF showed a downward concave chest wall V-P curve, in marked contrast to what happens in normal subjects [31]. The discrepancy in the behaviour of Est,w with PEEP between normal and COPD subjects, found in the present study, is consistent with their findings.

$E$ st,L increased with PEEP in both groups as expected from the shape of the lung V-P curve $[31,33]$. In our COPD group the largest increase of $E_{\mathrm{st}, \mathrm{L}}$ was observed when PEEP was raised from 10 to $15 \mathrm{cmH}_{2} \mathrm{O}$; that was presumably the pressure range in which relevant lung overdistension occurred. 
Lung and chest wall resistances. A decrease of $R \mathrm{~L}$, min with PEEP, observed in both our groups, was expected from the relationship between lung volume and airway resistance [34].

Pelosi et al. [5] and D'Angelo et al. [35] reported no change in either $\Delta R \mathrm{~L}$ or $\Delta R_{\mathrm{w}}$ when moderate PEEP levels (10 and $7.8 \mathrm{cmH}_{2} \mathrm{O}$, respectively) were applied to normal anaesthetized paralyzed subjects, in line with the results of the present study. In contrast, both $\Delta R \mathrm{~L}$ and $\Delta R \mathrm{w}$ increased with PEEP in our COPD subjects. It may be hypothesized that, in the mechanically heterogeneous COPD lung, PEEP enhances time constant inequalities among different alveolar units by dilating open, nonflow-limited alveolar pathways on one hand, while, on the other hand, recruiting previously flow-limited or functionally closed ones, which were virtually excluded from ventilation, to participate more actively in inspiratory $V \mathrm{~T}$ distribution. In this respect it should be noted that PEEP might actually result in a more even distribution of ventilation in COPD patients $[2,36]$, and that the increased additional resistance at higher PEEP levels might be due to the fact that a larger number of alveolar units with different time constants participate in ventilation. The increase of additional resistance with PEEP might also be due, at least in part, to enhanced stress relaxation. SHARP et al. [27] have shown that pressure losses due to stress relaxation increase considerably only when significant pulmonary hyperinflation occurs: this might have been the case in our COPD patients as suggested by the increase of $E$ st,L at high PEEP. Unfortunately, the interrupter technique does not allow differentiation between pendelluft and stress relaxation [9]. Independent of the underlying mechanism, the increase of $\mathrm{ARL}$ with PEEP offset the concomitant decrease of $R \mathrm{~L}$,min, with the consequence that PEEP did not prove effective in reducing total inspiratory lung resistance.

In conclusion, we have shown that, in patients with chronic obstructive pulmonary disease undergoing controlled mechanical ventilation for acute ventilatory failure, the chest wall may show markedly altered mechanical properties that add to the widely reported increase of lung resistance. Furthermore, positive end-expiratory pressure does not seem to acutely reduce total resistance or elastance of either the chest wall or the lung in these patients, at least during controlled mechanical ventilation.

\footnotetext{
Acknowledgements: The authors would like to thank N. Patroniti, for his skillful assistance in computer processing of the data, E. Moioli for the secretarial work, and the nurses and medical staff of the Monza S. Gerardo Hospital for their co-operation.
}

\section{References}

1. Broseghini C, Brandolese R, Poggi R, et al. Respiratory mechanics during the first day of mechanical ventilation in patients with pulmonary edema and chronic airway obstruction. Am Rev Respir Dis 1988; 138: 355-361.

2. Smith TC, Marini JJ. Impact of PEEP on lung mechanics and work of breathing in severe airflow obstruction. J Appl Physiol 1988; 65: 1488-1499.
3. Polese G, Rossi A, Appendini L, Brandi G, Bates JHT, Brandolese R. Partitioning of respiratory system mechanics in mechanically ventilated patients. J Appl Physiol 1991; 71: 2425-2433.

4. Katz JA, Zinn SE, Ozanne GM, Fairley BH. Pulmonary, chest wall and lung-thorax elastances in acute respiratory failure. Chest 1981; 80: 304-311.

5. Pelosi P, Cereda M, Foti G, Giacomini M, Pesenti A. Alterations of lung and chest wall mechanics in patients with acute lung injury: effects of positive end-expiratory pressure. Am J Respir Crit Care Med 1995; 152: 531-537.

6. Marini JJ. Should PEEP be used in airflow obstruction? (Editorial). Am Rev Respir Dis 1989; 140: 1-3.

7. Baydur A, Behrakis PK, Zin WA, Jaeger M, Milic-Emili J. A simple method for assessing the validity of the esophageal balloon technique. Am Rev Respir Dis 1983; 126: 788-791.

8. Behrakis PK, Higgs BD, Baydur A, Zin WA, MilicEmili J. Respiratory mechanics during halothane anesthesia and anesthesia-paralysis in humans. J Appl Physiol 1983; 55: 1085-1092.

9. Bates JHT, Baconnier P, Milic-Emili J. A theoretical analysis of interrupter technique for measuring respiratory mechanics. J Appl Physiol 1988; 64: 2204-2214.

10. Pepe PE, Marini JJ. Occult positive end-expiratory pressure in mechanically ventilated patients with airflow obstruction. Am Rev Respir Dis 1982; 126: 166-170.

11. D'Angelo E, Robatto FM, Calderini E, et al. Pulmonary and chest wall mechanics in anesthetized paralyzed humans. J Appl Physiol 1991; 70: 2602-2610.

12. Guerin C, Coussa ML, Eissa NT, et al. Lung and chest wall mechanics in mechanically ventilated COPD patients. J Appl Physiol 1993; 74: 1570-1580.

13. Kochi T, Okubo S, Zin WA, Milic-Emili J. Flow and volume dependence of pulmonary mechanics in anesthetized cats. J Appl Physiol 1988; 64: 441-450.

14. Armitage P. Statistica Medica. Milano, Feltnnelli Ed., 1977; pp. 249-254.

15. Thomas AJ, Supinski GS, Kelsen SG. Changes in chest wall structure and elasticity in elastase-induced emphysema. J Appl Physiol 1986; 61: 1821-1829.

16. Sharp JT, Van Lith P, Nuchprayoon C, Briney R, Johnson FN. The thorax in chronic obstructive lung disease. Am J Med 1968; 44: 39-46.

17. van Lith P, Johnson FN, Sharp JT. Respiratory elastances in relaxed and paralyzed states in normal and abnormal men. J Appl Physiol 1967; 23: 475-486.

18. Ranieri VM, Giuliani R, Cinnella G, et al. Physiologic effects of positive end-expiratory pressure in patients with chronic obstructive pulmonary disease during acute ventilatory failure and controlled mechanical ventilation. Am Rev Respir Dis 1993; 147: 5-13.

19. Bonmarchand G, Denis P, Weber J, Lerebours-Pigeonniere G, Massari P, Leroy J. Motor abnormalities of digestive and urinary tracts in patients on ventilator for acute exacerbation of chronic obstructive pulmonary disease. Dig Dis Sci 1989; 34: 1231-1237.

20. Wheeler PA. Sedation, analgesia and paralysis in the intensive care unit. Chest 1993; 104: 566-577.

21. Mutoh T, Lamm WJE, Hildebrandt J, Albert RK. Abdominal distension alters regional pleural pressures and chest wall mechanics in pigs in vivo. J Appl Physiol 1991; 70: 2611-2618.

22. Horrow JC, Abrams JT, van Riper DF, Lambson DL, Storella RJ. Ventilatory compliance after three sufentanyl-pancuronium induction sequences. Anesthesiology 1991; 75: 969-974. 
23. Mutoh T, Wayne J, Lamm WJE, Embree J, Hildebrandt $\mathrm{J}$, Albert RK. Volume infusion produces abdominal distension, lung compression, and chest wall stiffening in pigs. J Appl Physiol 1992; 72: 575-582.

24. Dechman G, Sato J, Bates JHT. Effect of pleural effusion on respiratory mechanics, and the influence of deep inflation, in dogs. Eur Respir J 1993; 6: 219-224.

25. Pride NB, Macklem PT. Lung mechanics in disease. In: Handbook of Physiology. The Respiratory System. Bethesda, MD. Am Physiol Soc, 1986, sect. 3, vol. III, pp. 659-692.

26. D'Angelo E, Prandi E, Tavola M, Calderini E, MilicEmili J. Chest wall interrupter resistance in anesthetized paralyzed humans. J Appl Physiol 1994; 77: 883887.

27. Sharp JT, Johnson FN, Goldberg NB, van Lith P. Hysteresis and stress adaptation in the human respiratory system. J Appl Physiol 1967; 23: 487-497.

28. Gay PC, Rodarte JR, Hubmayr RD. The effects of positive expiratory pressure on isovolume flow and dynamic hyperinflation in patients receiving mechanical ventilation. Am Rev Respir Dis 1989; 139: 621-626.

29. Hyatt RE, Mead J, Rodarte JR, Wilson TA. Changes in lung mechanics. Flow-volume relationships. In: Macklem PT, Permutt S, eds. The lung in transition between health and disease. New York, Dekker, 1979; pp. 73-112.
30. Rossi A, Santos C, Roca J, Torres A, Felez MA, RodriguezRoisin R. Effects of PEEP on VA/Q mismatching in ventilated patients with chronic airflow obstruction. Am J Respir Crit Care Med 1994; 149: 1077-1084.

31. Agostoni E, Mead J. Statics of the respiratory system. In: Handbook of Physiology. Respiration. Washington D.C. Am. Physiol. Soc., 1964, sect. 3, vol. I, pp. 387-409.

32. Ranieri VM, Giuliani R, Mascia L, et al. Chest wall and lung contribution to the elastic properties of the respiratory system in patients with chronic obstructive pulmonary disease. Eur Respir J 1996; 9: 1232-1239.

33. Gibson GJ, Pride NB, Davis J, Schroter RC. Exponential description of the static pressure-volume curve of normal and diseased lung. Am Rev Respir Dis 1979; 120: 799-811.

34. Briscoe WA, DuBois AB. The relationship between airway resistance, airway conductance and lung volume in subjects of different age and body size. J Clin Invest 1958; 37: 1279-1285.

35. D'Angelo E, Calderini E, Tavola M, Bono D, MilicEmili J. Effect of PEEP on respiratory mechanics in anesthetized paralyzed humans. J Appl Physiol 1992; 73: $1736-1742$.

36. Shim C, Chun KJ, Williams MH, Blaufox MD. Positional effects on distribution of ventilation in chronic obstructive pulmonary disease. Ann Intern Med 1986; 105: 346-350. 